\title{
Frequency and Predictors of Fistulae Occurrence after One Stage Repair with Radical Muscle Dissection for Complete Cleft Palate
}

\author{
Mohamad Saeed Amin ali ${ }^{1}$ MD; Samy abdelsattar eleowa ${ }^{1}$ MD; Mohamad osama ouf ${ }^{1}$ MD
}

\section{*Corresponding Author: Mohamad Saeed Amin ali drben700@gmail.com}

Received for publication May 19,2021;Accepted May 31, 2021; Published online May 31, 2021.

\section{Copyright The Authors published by Al-Azhar} University, Faculty of Medicine, Cairo, Egypt. Users have the right to read, download, copy, distribute, print, search, or link to the full texts of articles under the following conditions: Creative Commons AttributionShare Alike 4.0 International Public License (CC BY-SA 4.0).

doi: 10.21608/aimj.2021.76566.1476

${ }^{1}$ Plastic and Reconstructive Surgery Department, Faculty of medicine, Al-Azhar university (Girls) , Cairo, Egypt.

\begin{abstract}
Background: The main goal in management of patients with cleft palate is the anatomical closure of the defect, normal speech development, maxillofacial growth, and hearing without any complications.

Aim of the work: The objective of this study is to illustrate the frequency of fistula and fistula predictors in closure of complete cleft palate with radical palate muscle dissection.

Patients and methods: A prospective cohort study conducted in 20 patients who underwent cleft palate closure with radical muscle dissection as one stage repair in children aged between 9 months to 5 years old.

Results: Twenty patients had a cleft palate repair in a single stage. The overall occurrence of fistula formation was zero.

Conclusion: Anatomical repair of levator vile palatine muscle with complete dissection \& releasing it from its abnormal insertion in a defect of $10-12 \mathrm{~mm}$ could be an important factor for limitation of fistulae incidence after cleft palate repair.
\end{abstract}

Keywords: cleft palate ;one stage repair ;complete muscle dissection ;frequency of fistula.

Disclosure: The authors have no financial interest to declare in relation to the content of this article. The Article Processing Charge was paid for by the authors.

Authorship: All authors have a substantial contribution to the article.

\section{INTRODUCTION}

The most prominent congenital abnormalities in the oral and maxillofacial area have been cleft lip and/or palate. The total frequency of orofacial clefts is roughly one in 700 living births and the frequency of isolated cleft palate is roughly 0.5 per 1,000 living births. ${ }^{1}$

Closure of the physical defect with optimum velopharyngeal (VP) function and ideal speech, without impacting maxillofacial development or hearing, is the primary issue in cleft palate repair. ${ }^{1}$

Cleft palate repair can be done using a variety of surgical techniques. Such techniques are classified into one or two stages. Nevertheless, many recent studies showed that palate closure in a single stage can yield comparable maxillary outgrowth as compared to two-stage palate closure. ${ }^{2}$

There may be a controversy about performing complete radical dissection for the LVP muscle; however, there is general agreement about the importance of the release of its abnormal insertion that became an essential step during cleft palate repair for obtaining proper speech development afterwards. $^{3}$
In this study, a functional muscle repair with releasing it from its abnormal insertion was described.

Cleft palate repair can be jeopardized by a variety of issues, the most common of which is the development of a fistula that can cause hyper nasal speech, articulation problem, and food or liquid regurgitation into the nose. A variety of factors, including the patient's age, the surgeon's experience, and the cleft's width, may affect the success of palate repair. ${ }^{4}$

\section{PATIENTS AND METHODS}

The current study was conducted for 20 complete cleft palate patients' (12 male and 8 female). The patients aged from 9 months to 5 years. The patients were selected from those whom seeking treatment in the outpatient clinic in both plastic surgery department, Al-Hussein \& Bab Elsheria Hospital, Faculty of Medicine, Al-Azhar university (Cairo).

Children with syndromic cleft palate, major anomalies\& cardiac anomalies, bleeding disorders, recurrent cleft palate and sub mucous cleft were all excluded from the study. 
The procedure was explained in depth to the patient and his family using photos, video imaging, and conversations with other patients and their families who had experienced the operation.

An explanation of the study was given to the parents of the patients. A consent form was signed by the patients' parents involved in the study. And approved by Al-Azhar Ethical committee

Management:

Pre-operative preparation:

All patients completed medical history and clinical review as well as a pediatric review. Examination \& investigations as (CBC), (kidney function), (liver function), (coagulation profile), (viral markers), (echocardiogram) and (albumin) were achieved to clarify that patient was fit for surgery.

Operative Steps:

The surgical procedure done under general anesthesia with oral intubation. Under magnification using surgical magnifying loop 4.5X. and the tube secured with a 2.0 silk suture. (fig. 1 )

Flap design

An incision is made along the cleft, with preservation of nasal mucosa as much as possible by leaving about $3 \mathrm{~mm}$ on both sides.

Infusion of saline adrenalin (1/200000) into the mucosa of the hard and soft palate was injected, to help in hemostasis adding xylocaine to guard against adrenaline toxicity then wait for 15 minutes.

Oral Layer separation: The incision was made in both sides of the cleft to separate the nasal layer from the oral layer. Cutting mucosa along the design line. By using a single hook, the oral mucosa and gland layer was separated from the muscle layer using the small blunt dissector, Keeping the muscle intact and attached to nasal layer. (fig.2)

Stay sutures were applied on both sides of the separated oral layer, exposing the nasal mucosa and muscle, then the 2 vomerine flaps are dissected and elevated by a midline incision at the vomer, leaving about $3 \mathrm{~mm}$ from nasal mucosa at both sides of cleft then the incision was dissected using a blunt dissector, the 2 vomerine flaps sutured with the nasal mucosa of the cleft, the nasal mucosa of the soft palate was dissected and sutured directly with that of the other side. (Fig.3)

\section{Muscle Layer separation:}

From back to front, the incision was made from far to near. Dissection begins from the posterior rim of muscle and $5 \mathrm{~mm}$ from the midline. During the dissection avoid injury of the nasal mucosa as much as possible. (Fig. 4).

The surgeon detached palatopharyngeus muscle from its attachment to the rear boundary of the palatine shelves.

Separate the LVP as far as the Eustachian tube. Marke the position of the LVP on the nasal mucosa. This should be done on both sides. The palatine aponeurosis (white tissue) which is attached to posterior border of the hard palate now becomes more apparent should be dissected and separated.
The tensor veli palatine and the palatopharyngeus muscles should be separated from the nasal mucosa at the same time.

After finishing muscle dissection both the LVP and the palatopharyngeus from both sides should be sutured at midline by 4-0 or 5-0 vicryl. The knot should be kept in the inner side of the repair to avoid discomfort or exposure. Also, another important point the anterior part of the LVP when sutured make it protrude downwards. Now the oriented muscle sling can move freely to the posterior part of soft palate. (Fig. 5)

Elevation of mucoperiosteal flaps with dissection around greater palatine vessels and releasing incisions. dissection around the greater palatine nerve-vessel bundle will show the white bone near the root of the bundle. The periosteum here should be cut in order to freely mobilize two palatal flaps to facilitate closure without tension. (Fig. 6)

Closure of Oral Mucosa

oral layer closure using absorbable vicryl 4-0. in a simple mattress suturing technique. closure of the space between the oral and nasal layer is very important to stabilize the muscle position and prevention of hanging down of the two layers. (Fig. 7) post-operative care

left lateral position, oral care, feeding instructions (first three days post-operative: water and clear fluids only such as apple juice then any type of fluid for another week using a syringe directed downwards, avoiding hard diet and active suction at least for a month is very important).

Proper analgesia and antibiotics were prescribed.

First visit was 2 weeks after discharge. (Fig.8)

Statistical analysis:

Data were obtained, updated, encoded and entered in the version 20 of the Statistical Package for Social Science (IBM SPSS). Qualitative data were represented as numbers and percentages, whereas quantitative data were represented as mean, standard deviations and ranges when their distribution was identified as parametric.

The margin of error agreed was set to $5 \%$, with a $95 \%$ confidence interval. As a result, the p-value was deemed significant as follows:

$\mathrm{P}>0.05=$ non-significant $(\mathrm{NS}), \mathrm{P}<0.05=$ significant (S), $\mathrm{P}<0.001$ = highly significant (HS).

\section{RESULTS}

Our study showed zero incidence of fistulae formation in 20 patients (12 males and 8 females), age group ranged from 9 months to 5 years, with an average age of $1.25 \pm 0.57$ years. Table 1

$20 \%$ of our patients were veau 1 type and $80 \%$ were veau 2 . Table 2

Width of defect was ranging from $10-13 \mathrm{~mm}$. Table 3 


\begin{tabular}{||l|l|l|}
\hline \multicolumn{2}{|c|}{} & \multicolumn{1}{l|}{ No. $=20$} \\
\hline \multirow{2}{*}{ Age(years) } & Mean \pm SD & $1.25 \pm 0.57$ \\
\cline { 2 - 3 } Sex & Range & $0.75-2.5$ \\
\hline & Female & $8(40.0 \%)$ \\
\cline { 2 - 3 } & Male & $12(60.0 \%)$ \\
\hline
\end{tabular}

Table 1: Distribution of the studied cases according to Age and Sex

\begin{tabular}{||l|l|l|}
\hline Type of cleft & No. & $\%$ \\
\hline Veau I & 4 & $20.0 \%$ \\
\hline Veau II & 16 & $80.0 \%$ \\
\hline
\end{tabular}

Table 2: Distribution of the studied cases according to Type of cleft

\begin{tabular}{|l|l|}
\hline Width of defect & No. $=\mathbf{2 0}$ \\
\hline Mean \pm SD & $11.95 \pm 1.05$ \\
\hline Range & $10-13$ \\
\hline
\end{tabular}

Table 3: Distribution of the studied cases according to Width of defect

\begin{tabular}{|c|c|c|c|}
\hline \multirow{3}{*}{$\begin{array}{ll}\begin{array}{l}\text { Bleeding } \\
\text { transfusion }\end{array} & \text { require }\end{array}$} & & No. & $\%$ \\
\hline & Negative & 20 & $100.0 \%$ \\
\hline & Positive & 0 & $0.0 \%$ \\
\hline \multirow[t]{2}{*}{ Fever } & Negative & 17 & $85.0 \%$ \\
\hline & Positive & 3 & $15.0 \%$ \\
\hline \multirow[t]{2}{*}{ Chest infection } & Negative & 17 & $85.0 \%$ \\
\hline & Positive & 3 & $15.0 \%$ \\
\hline \multirow[t]{2}{*}{ Dehiscence } & Negative & 20 & $100.0 \%$ \\
\hline & Positive & 0 & $0.0 \%$ \\
\hline \multirow[t]{2}{*}{ Fistula } & Negative & 20 & $100.0 \%$ \\
\hline & Positive & $\mathbf{0}$ & $0.0 \%$ \\
\hline
\end{tabular}

Table 4: Distribution of the studied cases according to Bleeding require transfusion, Fever, Chest infection, Dehiscence and Fistula.

three (15\%) patients developed postoperative fever not exceeding 38.5 degree centigrade in the first postoperative day and controlled by antipyretic (paracetamole 15-30mg/kg/dose) suppository.

In the the second day the $3(15 \%)$ patients fever continued with development of tachypnea and nonproductive cough. Pediatric evaluation revealed development of tracheobronchitis and the condition was controlled well by double antibiotic coverage (ampicillin/sulbactam and ceftriaxone) and cough sedatives (natural derivatives). Table 4

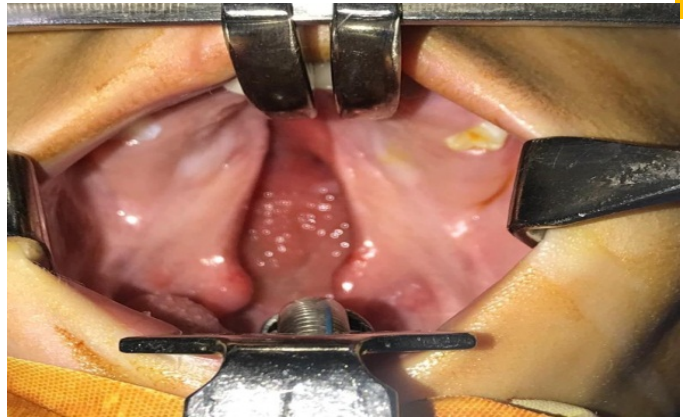

Surgery

Fig. 1: view of cleft palate

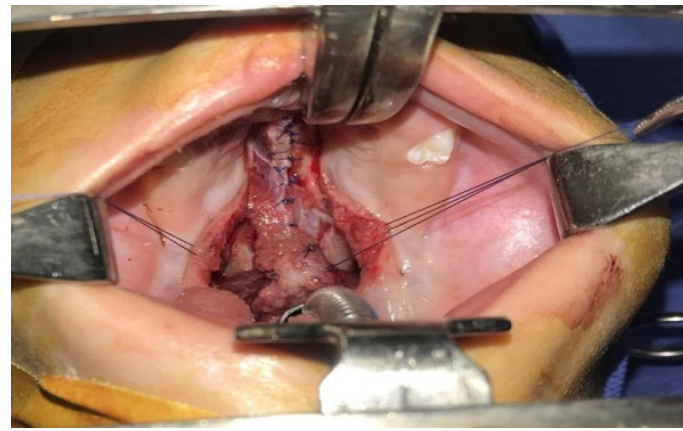

Fig. 2: oral layer separation

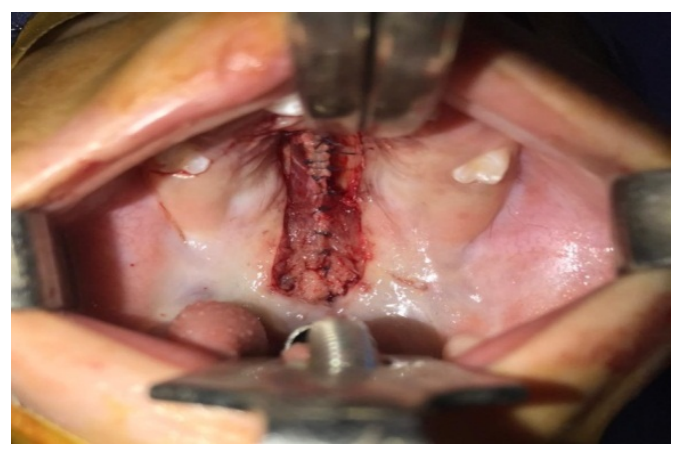

Fig. 3: closure of nasal layer

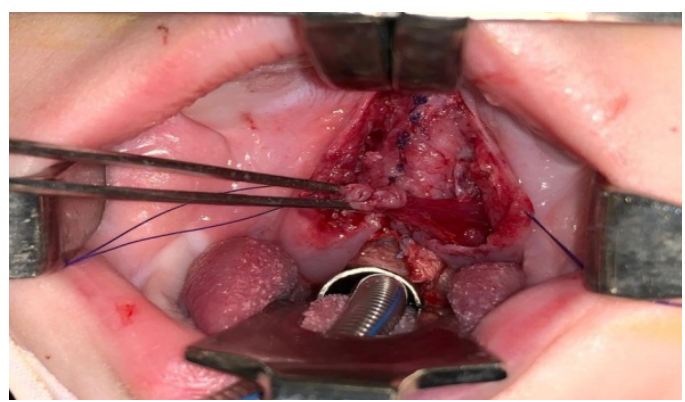

Fig. 4: muscle dissection

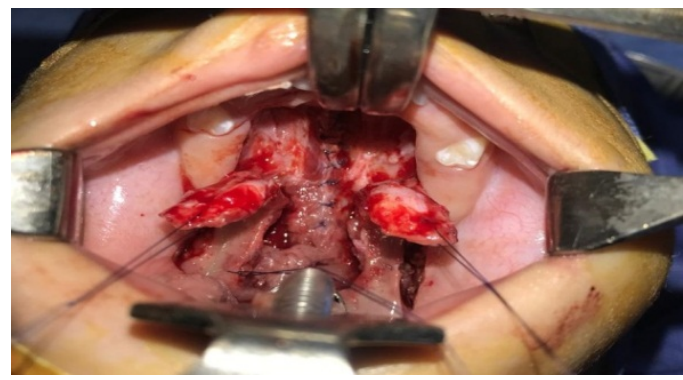

Fig. 5: muscle repair 


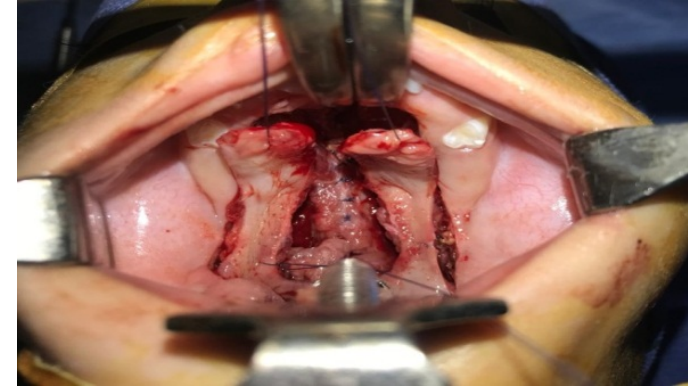

Fig. 6: elevation of mucoperiosteal flaps

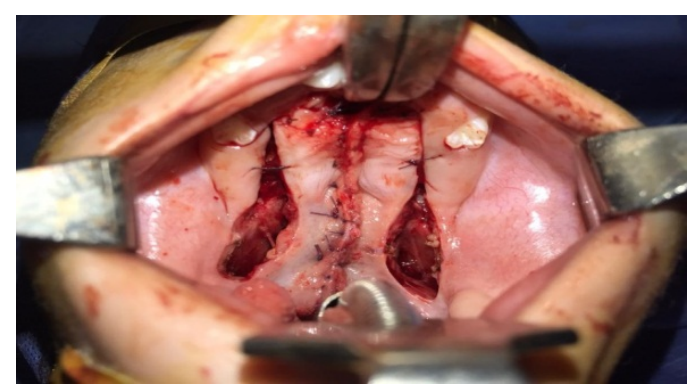

Fig. 7: closure of oral mucosa

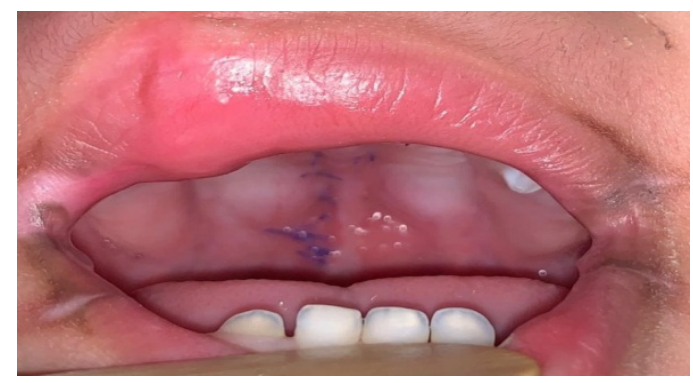

Fig. 8: 2 weeks after repair

\section{DISCUSSION}

The most common congenital craniofacial abnormalities assessed by a plastic surgeon are cleft lip and palate. These abnormalities are identified earlier, often using fetal ultrasound and magnetic resonance imaging (MRI). ${ }^{5}$

The incidence of cleft lip and palate among males is approximately 2times that of females, whereas the incidence for isolated cleft palate is about two-thirds that of females ${ }^{6}$

Cleft palate is a three-dimensional anomaly involving soft and skeletal tissue which shifts with growth and movement in the fourth dimension ${ }^{7}$

Palatoplasty (at least the soft palate) should be done around the ages of 6 and 12 months, according to most experts. There are three sets of palatoplasty techniques. The first is for hard palate repair, the second is for soft palate repair, and the third is dependent on the surgical schedule. Palatoplasty should be done in such a way that perfect speech is achieved without impacting maxillofacial development or hearing. ${ }^{8}$.

The dissection of the LVP muscle from its abnormal insertion at hard palate, nasal and oral mucosa first introduced by Braithwaite In 1968. the two opposite muscles dissected and oriented at the midline to form a sling which act as levator of soft palate for production of normal sounds This muscle was reported as the most abnormal muscle in cleft palate patients as it is abnormally attached to the bony edge of the cleft. ${ }^{9,10,11,}$

Many studies reported the improvement of speech after reconstruction of the LVP muscle. . ${ }^{12,13}$ some studies reported absence of statistical difference as regard speech after one stage palate repair with or without muscle reconstruction ${ }^{14,15}$ which was difficult to be assessed in our study because of our limited study time. In this study we propose clinically the outcome of radical muscle dissection regarding the fistulae rates

Relation between fistula rate and width of cleft is an important factor for fistulae formation. In our study the width of the cleft ranges from 10-13 mm and the incidence was zero as we operated on a small number of patients and this correlates with findings and conclusion of this article ${ }^{16 .}$ "The conclusions of these articles were that the cleft width of more than $15 \mathrm{~mm}$ and a ratio of cleft width to the sum of the palatal shelves' width of more than 0.48 have a statistically significant risk of fistulization".

In this study 3 cases (15\%) developed fever progressed as chest infection, such complains correlates with ${ }^{17}$. However, there was no bleeding and this could be due to injection of saline, adrenalin, good intraoperative hemostasis, smooth recovery and good pre and post-operative management

The objective of palate repair is to facilitate feeding and speech while maintaining facial growth unaffected. The repair should be carried out with a low risk of complications. Fistula formation following palatoplasty is believed to be caused by a variety of factors, including patient factors and treatment problems. ${ }^{18 .}$

Palatal fistula occurs when the main operative repair of a cleft palate fails to heal or starts to breakdown. Palatal fistula causes constant communication among the oral and nasal cavities, resulting in unpleasant signs which including nasal feed spillage, hypernasal speech, and articulation difficulties,could be avoided by meticulous hadling of tissue. One of the indicators of successful cleft palate repair is a reduced incidence of palatal fistula. ${ }^{19}$.

Cleft palate repair techniques have improved over time, however postoperative palatal fistula persists a difficult complication. The failure of wound healing caused by excessive tension, infection, or hematoma causes a postoperative palatal fistula. Excessive tension during closure of broad palatal clefts makes them particularly vulnerable to the development of a postoperative fistula. The frequency of postoperative fistula formation varies depending on the surgical technique used, however typically falls around 2.4 to $35 \%$. ${ }^{20}$

Repair under tension is the main trigger of oronasal fistula (ONF) development, and the accessible tissue to repair the palate appears to be insufficient. The risk of developing the ONF is higher in these instances, but it could be avoided in the hands of a skilled practitioner. Another factor is postoperative infection that is rare in young children. During palatoplasty, vascular incidents may result in the loss of the flap that is a relatively rare cause of ONF development Furthermore, the use of diathermy inadvertently, especially near the larger palatine 
pedicle, may compromise the blood flow of the mucoperiosteal flap, resulting in an ONF. ${ }^{21}$

Fistula rates have been recorded to vary from $5 \%$ to $60 \%$ in many studies ${ }^{22,23}$. According to some studies, the frequency of palatal fistulas following cleft palate repair ranges from 3 to $45 \%{ }^{24,25}$. According to other studies, palatal fistulas happen in $5-20 \%$ of patients following palatal surgery. ${ }^{18,26}$

In this study no palatal fistula was encountered. This could be explained by following up of standard technical steps, meticulous dissection and the presence of narrow defects. However this study represent a limited number of cases but could be considered as a preliminary finding which highlight its importance of investigating the idea of radical muscle dissection. Some studies reported absence of fistula development after cleft palate repair that supports our results. ${ }^{19,20}$

This could be linked to the exclusion of patients with very wide palatal clefts and smaller number of the study group. Some studies reported that fistula rate was higher for the more sever degree of clefting. Also, many other studies reported that the width of the cleft at the time of cleft palate repair is essential in the development of fistulas.

In their research, Landheer discovered a high rate of fistula formation following cleft palate repair. Despite the fact that the population of the study had not been randomized, the findings indicate that a two-stage closure had a higher incidence of fistula formation than a one-stage closure, and the width of the cleft during repair was essential to the development of fistulae ${ }^{27}$

\section{CONCLUSION}

Anatomical repair of levator vile palatine muscle with complete dissection \& releasing it from its abnormal insertion in a defect of 10-12 mm could be an important factor for limitation of fistulae incidence after cleft palate repair.

\section{REFERENCES}

1. El-Anwar, Mohammad \& Nofal, Ahmed \& Khalifa, Mohamed \& Saeed, Amal.. Use of Autologous Platelet-Rich Plasma in Complete Cleft Palate Repair. The Laryngoscope. (2016) 126 10.1002/lary.25868.

2. Mustafa Chopan, Lohrasb Sayadi and Donald R. Laub (March 22nd 2017). Surgical Techniques for Treatment of Unilateral Cleft Lip, Designing Strategies for Cleft Lip and Palate Care, Mazen Ahmad Almasri, IntechOpen, DOI: 10.5772/67124. Available from: https://www.intechopen.com/books/designingstrategies-for-cleft-lip-and-palate-care/surgicaltechniques-for-treatment-of-unilateral-cleft-lip

3. Heidsieck DS, Smarius BJ, Oomen KP, Breugem CC. The role of the tensor veli palatini muscle in the development of cleft palate-associated middle ear problems. Clin Oral Investig. 2016;20(7):1389-401. doi:10.1007/s00784-016-1828-x
4. Mahajan RK, Kaur A, Singh SM, Kumar P. A retrospective analysis of incidence and management of palatal fistula. Indian $J$ Plast Surg. 2018;51(3):298-305. doi:10.4103/ijps.IJPS_84_18

5. Kosowski TR, Weathers WM, Wolfswinkel EM, Ridgway EB. Cleft palate. Semin Plast Surg. 2012;26(4):164-9. doi:10.1055/s-0033-1333883

6. Mossey PA, Modell B. Epidemiology of oral clefts 2012: an interna- tional perspective. Front Oral Biol. 2012;16(4):1-18.

7. Bearn D, Mildinhall S, Murphy T.Cleft lip and palate care in the United Kingdom: the Clinical Standards Advisory Group (CSAG) Study. Part 4: outcome comparisons, training, and conclusions.Cleft Palate Craniofac J. 2001; 38 : 38-43.

8. Agrawal, Karoon. "Cleft palate repair and variations.” Indian journal of plastic surgery : official publication of the Association of Plastic Surgeons of India vol. 42 Suppl,Suppl (2009): S102-9. doi:10.4103/0970-0358.57197

9. Braithwaite F, Maurice DG. The importance of the Levator Palatini muscle in cleft palate closure. $\mathrm{Br} \mathrm{J}$ Plast Surg.1968;2:60 -2

10. Koch, K. H., Grzonka, M. A., \& Koch, J. Pathology of the palatal aponeurosis in cleft palate. The Cleft Palate-Craniofacial Journal. 1998; 35(6), 530-4.

11. Ha S. The Levator Veli Palatini Muscle in Cleft Palate Anatomy and Its Implications for Assessing Velopharyngeal FunctionDisorders, Korean Journal of Communication Disorders. 2007; 12:77- 89.

12. Cutting CB, Rosenbaum J, Rovati L. The technique of muscle repair inthe cleft soft palate. Oper Tech Plast Reconstr Surg. 1995; 2:215-22.

13. . Sommerlad BC. A technique for cleft palate repair. Plast Reconstr Surg. 2003; 112:1542-8.

14. Marsh JL, Grames LM, Holtman B. Intravelar veloplasty: a prospective study. Cleft Palate J. 1989; 26:46-50.

15. Gunther E, Wisser JR, Cohen MA, Brown AS. Palatoplasty: Furlow's double reversing Z-plasty versus intravelar veloplasty. Cleft Palate Craniofac J. 1998; 35:546-9.

16. Parwaz MA, Sharma RK, Parashar A, Nanda V, Biswas G, Makkar S. Width of cleft palate and postoperative palatal fistula-do they correlate? $J$ Plast Reconstr Aesthet Surg. 2009;62:1559-63

17. Mohamad abdel razek AL-AZHAR ASSIUT MEDICAL JOURNAL VOL 13 , NO 1 , JANUREY 2015 
18. Becker M,Hansson E. Low rate offistulaformation after Sommerlad palatoplasty with or without lateral incisions: an analysis of risk factors for formation of fistulas after palatoplasty. J Plast Reconstr Aesthet Surg. 2013; May; 66(5):697-703.

19. Katusabe JL, Hodges A, Galiwango GW, Mulogo EM. Challenges to achieving low palatal fistula rates following primary cleft palate repair: experience of an institution in Uganda. BMC Res Notes. 2018;11(1):358. Published 2018 Jun 7. doi:10.1186/s13104-018-3459-6

20. Ha ,j.h , jeong, y., koo, y.t et al . effect of collage matrix on postoperative palatal fistula in cleft palate repair .scy rep 10,15236 (2020)

21. Sadhu, Partha. "Oronasal fistula in cleft palate surgery.” Indian journal of plastic surgery : official publication of the Association of Plastic Surgeons of India vol. 42 Suppl,Suppl (2009): S123-8. doi:10.4103/0970-0358.57203

22. Emory RE, Clay RP, Bite U, Jackson IT.Fistula formation and repair after palatal closure: an institutional perspective. Plast Reconstr Surg. 1997; 99:1535-8.
23. Muzaffar AR, Byrd HS, Rohrich RJ, Johns DF, LeBlanc D, Beran SJ, Anderson C, Papaioannoua AA.Incidence of cleft palate fistula: an institutional experience with two-stage palatal repair. Plast Reconstr Surg. 2001;108:1515-8

24. Lu Y, Shi B, Zheng Q, Hu Q, Wang Z.Incidence of palatal fistula after palatoplasty with levatorveli palatini retropositioning according to Sommerlad. $\mathrm{Br}$ J Oral Maxillofac Surg. 2010;48:637-40.

25. Andersson EM, Sandvik L, Semb G, Abyholm F.Palatal fistulas after primary repair of clefts of the secondary palate.Scand J Plast Reconstr Surg Hand Surg. 2008; 42:296-9.

26. Phua YS, De ChalainT.Incidence of Oronasal Fistulae and Velopharyngeal Insufficiency After Cleft Palate Repair: Cleft Palate-Craniofacial Journal. 2008 Vol. 45 No. 2 March :172-8.

27. ILandheer ja , breugem md ,van der molen m. fistula incidence and predictors of fistula occurance after cleft palate repair : two stage closureversus one-stage closure . cleftpalate cranioface j . 2010;47:623-630 